\title{
DIE OPLEIDING VAN STADS- EN STREEKBEPLANNERS
}

\section{IN SUID-AFRIKA}

\section{Agtergrond en die huidige posisie}

Die eerste kursus vir die opleiding van beplanners in die Republiek van Suid-Afrika is twintig jaar gelede aan die Universiteit van die Witwatersrand ingestel. Sowat agt jaar gelede het die Universiteit van Natal met 'n soortgelyke kursus begin en twee jaar daarna het die Universiteit van Pretoria hulle voorbeeld gevolg.

Hierdie drie kursusse is nagraads sowel as na-uurs. Hulle is daarop ingestel om verdere opleiding te verskaf aan persone wat reeds 'n kursus in stadsbeplanning gedurende hulle voorgraadse opleiding gevolg het, m.a.w. die doel van hierdie kursusse is om meer gevorderde opleiding in beplanning vir argitekte, ingenieurs en landmeters beskikbaar te maak. Hierdie kursusse is dus geskoei op die Britse patroon, wat 'n halfeeu gelede ontstaan en sedertdien min verandering ondergaan het.

Kort voor die Eerste Wêreldoorlog het 'n groep argitekte, ingenieurs en landmeters in Londen byeengekom en die "Town Planning Institute" gestig. Lede van hierdie professies was veral gemoeid met die fisiese aspekte van dorpsbeplanning d.w.s. die onderverdeling van grond, die voorsiening van paaie en ander dienste en die ontwerp en konstruksie van geboue. Die stad is ook gesien as 'n suiwer fisiese struktuur soos 'n gebou of 'n rioolwerk.

Die pasgestigte instituut vir stadsbeplanners het, soos alle institute, sekere toelatingsvereistes neergelê, wat lidmaatskap van die instituut beperk het tot lede van die drie professies wat ook 'n voorgeskrewe eksamen in stadsbeplanning afgelê het. Daar was 'n ander groep lede, regslede ( „legal members"), maar hulle is nie hier ter sprake nie. Daar was geen opleidingsfasiliteite nie en die instituut het hom daarvoor beywer. Om 'n goeie standaard te handhaaf het daardie instituut 'n leerplan opgestel en jaarliks eksamens gestel wat afgelê moet word voordat argitekte, ingenieurs en landmeters as lede van die instituut toegelaat kon word. Sekere Britse universiteite het mettertyd kursusse vir stadsbeplan- 
ners ingestel, gebaseer op die instituut se leerplan. Die instituut het ook die reg voorbehou om kursusse wat deur universiteite gedoseer is, te ondersoek en sodoende vas te stel of dit aan die vereiste standaard voldoen. Dit was inderdaad prysenswaardig en 'n groot stap vorentoe deur persone wat self weinig, indien enige, opleiding in beplanning gehad het.

Die Britse instituut het baie inisiatief aan die dag gelê, want daar is besef dat persone sonder 'n basiese kwalifikasie in enige van die drie tegniese professies ook die geleentheid gegee moes word om as beplanners te kwalifiseer. Hierdie persone moes 'n sogenaamde ,intermediêre eksamen" aflê om hulle op gelyke voet met die professies te bring. Hierdie stelsel is vandag nog van toepassing.

Die Suid-Afrikaanse Instituut vir Beplanners wat 'n paar jaar gelede gestig is, is op die Britse lees geskoei en het dieselfde toelatingsvereistes en dieselfde magte ten opsigte van opleiding. Die plaaslike instituut stel nie eksamens nie maar behou die reg om ondersoek in te stel na die standaard van kursusse wat aan universiteite gedoseer word. Die instituut kan aan die universiteit voorskryf wat die inhoud van enige kursus moet wees indien die erkenning van die instituut verlang word, en ipso facto is lidmaatskap van die instituut beperk tot erkende kursusse.

Die nagraadse kursusse wat drie universiteite in die Republiek aanbied wyk gevolglik baie min van die Britse stelsel af, en soos ek reeds aangedui het, is basies dieselfde as wat dit ' $n$ halfeeu gelede was. Die Britse benadering in die opleiding van beplanners is baie prakties georiënteer, synde 'n direkte uitvloeisel van die Industriële Rewolusie. Die instituut is ' $n$ vakbond eerder as ' $n$ akademiese instelling.

Hierdie praktiese benadering is in die verlede verder versterk deurdat klasse aan ons universiteite dikwels gegee of ten minste aangevul is deur praktiserende beplanners, en hulle is gereeld as eksterne eksamenatore aangewys. Gevolglik het die klem geval op stadsbeplanning en veral op die ontwerp van dorpsuitbreidings en die opstel van dorpsaanlegskemas. Hierdie "down to earth", praktiese benadering kan as die eerste fase in die opleiding van beplanners beskou word.

Die tweede fase in die opleiding het so pas begin. Dit is die akademies-teoretiese beskouing. Die teoretiese raamwerk word beklemtoon eerder as praktiese aspekte, en onderrig is in die hande van voltydse dosente. Die omvang of 
dimensie is uitgebrei om die streek ook in te sluit, d.w.s. 'n dorp en sy streek word nie as twee onafhanklike entiteite beskou nie maar as twee organismes simbioties verwant.

Daar is vanselfsprekend baie wrywing tussen die ondersteuners van die twee fases. Die praktiese man beskou al die teorie as ' $n$ mors van tyd en kla dat studente nie van onmiddellike waarde vir hom is nie. Vir die teoretici is hy meer as 'n tegnikus wat 'n potlood en 'n skaal kan gebruik en wie se kennis van beplanning beperk is tot die hellings vir rioolpype en die wydte van strate.

As stads- en streekbeplanning as 'n volwaardige universiteitskursus beskou wil word, en myns insiens bestaan daar geen twyfel dat dit daarvoor kwalifiseer nie, moet die teoretiese fondament nog verder versterk word en moet die gebruik om op praktiese hulpmiddels vir beplanning te konsentreer gestaak word. Dié moet 'n ondergeskikte rol in opleiding speel en geen universitêre kursus moet afgewater word met die spesifieke doel om hierdie praktiese aspekte in te sluit nie. Die student moet eerstens geleer word om te dink, om te analiseer en te interpreteer, en daarna om te doen.

Die tweede fase in die opleiding van beplanners het ' $n$ groot stoot vorentoe gekry deur die instelling van 'n voltydse voorgraadse kursus aan die Universiteit van die Witwatersrand aan die begin van hierdie jaar en die gepaardgaande skepping van 'n leerstoel vir Stads- en Streekbeplanning, die eerste in die Republiek. 'n Soortgelyke kursus sal in 1966 aan die Universiteit van Pretoria begin. 'n Leerstoel is ook aan die Universiteit van Kaapstad ingestel, en daar sal waarskynlik in 1966 'n aanvang met 'n nagraadse kursus gemaak word.

Van 1966 af sal die posisie wat die opleiding van beplanners betref min of meer soos volg wees:

3 voorgraadse kursusse;

4 nagraadse kursusse (hoofsaaklik vir argitekte, ingenieurs en landmeters).

\section{Die taak van die beplanner}

Voordat die opleiding van beplanners in detail bespreek word, is dit nodig om eers vas te stel wat sy bydrae in die moderne samelewing is. Beplanning as ' $n$ afsonderlike professie het, soos ek reeds aangedui het, ongeveer vyftig jaar 
gelede ontstaan en opleiding vir hierdic professie het slegs twintig jaar gelede in die Republiek begin.

Alhoewel die beplanningsprofessie baie jonk is, het beplanning, en veral stadsbeplanning, lank voor daardie tyd plaasgevind. Daar is voorbeelde van beplande dorpe en verwante menslike aktiwiteite in die Midde-Ooste tussen 6,000 en 8,000 jaar gelede. Die Grieke en Romeine het die beplanning van dorpe baie verder gevoer, en ook gedurende die Middeleeue en die Renaissance-tydperk is nuwe dorpe beplan, en bygevoeg tot bestaande dorpe.

Die groot behoefte van beplanning het egter ontstaan as gevolg van die geweldige proses van verstedeliking wat op die Industriële Rewolusie gevolg het. Tegnologiese ontwikkeling, veral nuwe vorms van vervoer en beter dienste, het feitlik onbeperkte uitbreiding van dorpe en stede moontlik gemaak. Nuwe boutegnieke het aanleiding gegee tot die wolkekrabber met sy geweldige konsentrasie van mense. Daar was opgeleide persone wat toesig gehou het oor elk van die fasette van ontwikkeling en daarvoor verantwoordelik was, maar niemand was gemoeid met die dorp as geheel en niemand het die uiteenlopende gekoördineer nie. Die beplanningsprofessie is spesifiek vir hierdie doel in die lewe geroep.

Die geweldige snelheid van beweging van persone, van goedere en van idees het die mens feitlik 'n ruimtewese gemaak. $\mathrm{Hy}$ is nie langer plekgebonde nie. ' $\mathrm{n}$ Geografiese gebied kan ook nie langer in isolasie beskou word nie. Die dorp en streek en dorpe onderling beïnvloed mekaar en is van mekaar afhanklik. Waar die beplanner hom voorheen op die dorp alleen toegespits het, het hy vandag met 'n groter geheel te doen.

Die hooftaak van die stads- en streekbeplanner is dus om enige gebied as ' $n$ geheel te sien. $E k$ wil egter beklemtoon dat dit nie vir elke geringe probleempie nodig is om na die stadstreek te kyk nie. Elke fisiese probleem moet binne sy eie invloedsgebied gesien en binne daardie raamwerk opgelos word.

In die praktyk word beplanners geëmplojeer deur plaaslike besture, die provinsiale administrasies en staatsdepartemente.

Die plaaslike bestuur verwag van die beplanner dat hy 'n dorpsaanlegskema sal kan opstel en administreer, planne vir nuwe dorpsuitbreidings sal kan ontwerp en kommentaar sal kan lewer op dorpsplanne wat deur private persone inge- 
dien word. Met ander woorde, die dorpsbeplanner moet ' $n$ deskundige wees op die terrein van grondgebruik, sowel as die onderlinge verwantskap tussen die verskeie gebruike. Grondgebruik is egter afhanklik van verkeer en vervoer, en die stadsbeplanner moet ingelig wees oor die wisselwerking tussen grondgebruik en vervoer. Hy hoef egter nie 'n verkeersdeskundige te wees nie. Die beplanner moet ook weet watter sosio-ekonomiese faktore grondgebruik beïnvloed.

Die taak van die beplanner op provinsiale vlak strek oor 'n baie wyer veld. Hy moet objektiewe kritiek oor die werk van die beplanner op plaaslike bestuursvlak kan lewer en veral die aandag vestig op die invloed van die streek op die dorp, en van die dorp op die streek op daardie tydstip en vlak.

Die fisiese beplanner op nasionale vlak moet in die eerste instansie die nasionale nedersettingspatroon en die onderlinge verwantskap tussen die verskeie streke in 'n land bestudeer. Sy kennis van dorpsbeplanning hoef nie noodwendig so diepgaande soos die op die ander twee vlakke te wees nie, maar is nogtans baie belangrik omdat dorpe die fokuspunte van ontwikkeling is.

\section{Die benadering van die fisiese beplanner}

Die beplanner se benadering tot fisiese ontwikkeling moet dinamies wees, omdat beplanning hoofsaaklik op die toekoms georiënteer is. Een van die groot leemtes in beplanningsaktiwiteite vandag is dat onvoldoende aandag aan toekomstige ontwikkeling geskenk word. Een van die redes hiervoor is die tekort aan opgeleide personeel en dat huidige probleme gewoonlik hoër prioriteit moet geniet omdat die gemeenskap direk daardeur geraak word en dikwels ongerief moet verduur. Die ander rede is dat die beplanner sowel as persone van veruante dissiplines geneig is om alles uit 'n statiese gesigspunt te benader. Die stad word gesien as 'n aantal geboue wat met strate, kragdrade en miskien rioolpype verbind is. Dit behoort, volgens my beskeie mening, gesien te word as die konsentrasiepunt van al die verskeidenheid van menslike aktiwiteite.

Daar is 'n menigte faktore wat tot al hierdie aktiwiteite aanleiding gee, o.a. ekonomiese, fisiologiese, sosiale, politieke, estetiese, klimatologiese faktore ens. Hierdie faktore en hulle spesifieke prikkel verander met die loop van tyd, of mag 
selfs in sommige gevalle baie snel verander. Die tegnologie speel veral 'n baie belangrike rol, want as gevolg van nuwe uitvindsels word nuwe behoeftes geskep en ou behoeftes op 'n nuwe wyse bevredig.

$\mathrm{Al}$ die faktore wat gesamentlik menslike aktiwiteite stimuleer en sodoende aanleiding gee tot die fisiese ontwikkelingspatrone wat ons op die oppervlak van die aarde gewaar, moet egter beskou word as die basiese struktuur van 'n dorp en/of streek, afhangende van waar die aktiwiteite konsentreer. Om te kan beplan moet die fisiese beplanner die onderliggende struktuur van die dorp of streek verstaan en hoe dit met verloop van tyd verander het. Hy moet ook 'n formele of visuele struktuur met 'n spesifieke abstrakte struktuur kan assosieer. Hy kan nie en hoef nie 'n deskundige te wees op die terrein van elke menslike aktiwiteit nie.

Die beplanner is by uitstek ' $n$ raadgewer en nie 'n uitvoerder nie. Instansies op elke vlak het beleide wat in fisiese vorms tot uitdrukking kom. 'n Nuwe beleid of 'n wysiging van 'n bestaande beleid gee aanleiding tot ' $n$ verandering in die bestaande fisiese patroon, en die beplanner moet in staat wees om die betrokke gesag of instansie met raad te kan bedien oor die fisiese gevolge van beleidsbesluite. Ten einde implikasiestudies van hierdie te kan doen en om projeksies vir die toekoms te kan maak, moet die beplanner 'n insig hê in die basiese struktuur van menslike konsentrasies, en hulle dinamies benader. Indien hy nie oor daardie kwaliteite beskik nie sal enige plan wat hy mag opstel, verouderd wees nog voordat dit uitgevoer is.

\section{Opleiding}

$\mathrm{Na}$ aanleiding van die taak en die benadering van die beplanner wat baie kortliks geskets is, moet gepoog word om sekere riglyne vir opleiding neer te lê.

(a) ' $n$ Voor- of 'n nagraadse kursus.

Hierdie spesifieke punt is reeds baie bespreek sonder om tot 'n gevolgtrekking te kom.

'n Voorgraadse kursus word gewoonlik afgekeur vanweë die onrypheid van die studente. Persoonlik kan ek hierdie argument glad nie aanvaar nie. Indien 'n persoon na 'n vierjarige kursus aan 'n universiteit nie ryp genoeg is vir stadsen streekbeplanning nie, is hy myns insiens ewe onryp vir 
meeste ander professies of dissiplines. Tweedens, moet dit in gedagte gehou word dat rypheid kom as gevolg van ervaring en die toepassing van kennis, en dat 'n persoon nie noodwendig ryper sal wees as hy meer jare op universiteitsbanke deurbring nie.

Die doel van 'n voorgraadse kursus is reeds o.a. om die tyd wat dit vandag neem om as 'n beplanner te kwalifiseer, te verminder deur onnodige kursusse weg te laat. Elke dissipline het 'n spesifieke benadering, en die van beplanning sal moontlik beter tot studente deurdring indien hulle nie eers in ' $n$ ander professie kwalifiseer nie. Die belangstelling in beplanning sal waarskynlik ook groter uees onder studente wat direk na matriek hierdie rigting inslaan.

'n Ander belangrike voordeel van 'n voorgraadse kursus is dat dit gewoonlik voltyds gedoseer word en dat die student meer geleentheid sal hê om interessante aspekte van beplanning te bespreek sowel as om boeke te lees. Deeltydse studente lees gewoonlik nooit enige boek of tydskrif nie.

In die veld van beplanning is daar baie verwante dissiplines soos sosiologie, ekonomie, geografie ens. waarvan die beplanner heelwat moet weet. In die tyd tot die beskikking van na-uurse opleiding moet hierdie vakke onvermydelik afgeskeep word.

Die belangrikste verskil tussen voor- en nagraadse opleiding soos dit vandag bestaan is dat die huidige nagraadse kursusse vir spesialiste in die tegniese professies bedoel is met ander woorde 'n spesialis kry 'n breë beplanningsagtergrond. Die voorgraadse kursus daarenteen gee 'n algemene opleiding in beplanning waarop verder gebou kan word deur nagraadse studie en gevolglike spesialisering in een of ander faset van beplanning. Ons het vandag nie persone wat in een of ander rigting van beplanning gespesialiseer het nie, en hulle behoort 'n uaardevolle toevoeging tot die beplanningsprofessie uit te maak. Die feit dat persone op 'n jonger leeftyd as beplanners sal kwalifiseer, sal hopelik meer nagraadse studie en meer navorsing as gevolg hê.

Die tekort aan beplanners is grootliks toe te skryf aan die huidige vorm van opleiding. ' $n$ Professionele persoon is selde bereid om onder aan die beplanningsleer te begin, aangesien hy ook oor 'n ander kwalifikasie beskik. Met die voorgraadse kursus sal persone jonger wees wanneer hulle kwalifiseer en miskien bereid wees om laer besoldigde poste te vul. 
'n Ander vorm van nagraadse opleiding wat ons nog nie in die Republiek het nie maar wat deur sekere inrigtings oorweeg word, is 'n tweejarige kursus vir gegradueerdes in ander dissiplines wat 'n baie belangrike rol in fisiese beplanning speel. Dit word hoofsaaklik beoog om ekonome, geograwe en sosioloë op hierdie uyse na die beplanningsprofessie te lok. So 'n kursus sal, net soos die bestaande nagraadse opleiding vir die tegniese professies, ook 'n toevoeging tot 'n bestaande spesialisme wees behalwe dat die klem waarskynlik op analitiese metodes en nie op ontwerp sal val nie. Dit kom daarop neer dat hierdie persone geleer sal word om in terme van ruimte te dink.

Dit is moeilik om te oordeel watter van hierdie opleidingsmetodes die beste vrugte sal afwerp, omdat ons tot dusver nog net die resultate van een metode ken. Op die huidige tydstip is daar ' $n$ behoefte aan persone van al die verskillende rigtings en daar is skynbaar geen rede waarom al drie die kursusse nie aan een universiteit gedoseer kan word nie. Die beplanningsdepartement sal baie baat, as dit daarin slaag om al hierdie dissiplines saam te trek en op die lang duur sal 'n baie beter beplanningskursus opgestel kan word, want die ander departemente sal die probleem van die beplanner beter kan verstaan.

Indien 'n universiteit beplanningsopleiding aanbied is dit noodsaaklik dat die departement of afdeling van beplanning alle beplanningskursusse doseer. Spesiale kursusse kan opgestel word om aan die vereistes van ander departemente te voldoen. Benewens kursusse vir argitekte, ingenieurs en landmeters kan spesiale kursusse vir publiek administrasie-studente en ander belangstellendes aangebied word.

Alhoewel 'n departement van beplanning aan die begin baie min studente sal hê, skyn dit nogtans noodsaaklik dat 'n afsonderlike departement of instituut vir die doel geskep word en dat hy nie te land deur 'n ander departement met ' $n$ ander beskouing beheer word nie.

(6) 'n Kernprogram vir beplanners.

Vir die doeltreffende opleiding van stads- en streekbeplanners moet 'n sterk kernprogram opgestel word. "City planning has much to learn from other fields of study, but a sound planning education cannot be provided by exposing a student to bits and pieces of many subjects given in the 
different departments and schools, as is done to-day by many of the planning schools" (Harry S. Perloff: Education of City Planners: Past, Present and Future. Journal of the American Institute of Planners. Vol. XXII, No. 4, 1956).

Daar bestaan glad nie duidelikheid oor die inhoud van die kernkursus nie, maar dit is ongetwyfeld dat die ,geskiedenis van stedebou" 'n deel daarvan moet wees. Die benaming van hierdie vak is verkeerd en word ook dikwels verkeerd benader. Die vorm, ontwikkeling en groei van dorpe en stede moet gesien word as die mens se aanpassing by sy omgeuing as gevolg van sekere prikkels, maar binne die raamwerk van fisiese en intellektuele beperkings.

Die kernprogram moet gebou word rondom basiese beginsels en tegnieke van beplanning, baie waarvan ontleen is aan ander dissiplines soos ekonomie en sosiologie. Die kern kursus moet die fondament wees uaarop die beplanner in die toekoms verder kan uitbou, ongeag die rigting waarin hy in die toekoms mag spesialiseer, m.a.w. dit sal basies eenders wees.

Die kernprogram moet daarop toegespits wees om by die student die gewoonte aan te kweek om streke of probleemgebiede as 'n geheel te sien en om hom te leer om met komplekse elemente te werk. 'n Analitiese benadering is 'n ander gewoonte wat aangewakker moet word.

(c) Byvakke.

Alhoewel 'n beplanner 'n goeie algemene universitêre opleiding moet kry is daar sekere tegnieke wat ook opgedoen moet word. Vir doeleindes van analise en interpretasie van gegewens is statistiese metodes onontbeerlik. In die laer poste is dit noodsaaklik dat beplanners self die verwerking van sekere gegewens uitvoer en die resultate interpreteer. $\mathrm{Na}$ aanleiding daarvan behoort hy te leer dat die verwerking van gegewens sonder om die resultate te interpreteer, nutteloos is en andersyds dat tyd verspil word deur nuttelose gegewens te verwerk.

Hierdie soort les is baie belangrik, want beplanners is geneig om groot hoeveelhede inligting in te samel wat nooit gebruik word nie.

'n Kursus in wiskunde is baie handig, omdat daar vandag baie gebruik gemaak word van wiskundige modelle.

Wiskunde behoort 'n keusevak te wees omdat baie studente die vak te moeilik vind, en dit wel moontlik is om 
die grondbeginsels van wiskundige modelle, hulle gebruik en beperkings, te begryp sonder gevorderde wiskunde. Wiskunde en wiskundige statistiek behoort egter nie as 'n keusevak uitgeskakel te word vir die student wat self tot drie kursusse daarin wil aflê nie, omdat die syferrekenaar al hoe meer in beplanning gebruik word. Deur wiskundige modelle te gebruik kry beplanning 'n dieper wetenskaplike inslag.

Van al die ander vakke skyn dit dat ekonomie die belang rikste is. Die mikro- en die makronedersettingspatroon van 'n land word grootliks deur ekonomiese faktore bepaal en andersyds is die ekonomiese aspekte van enige beplanningsprojek dikwels die deurslaggewende faktor. Die rol van die ekonoom in beplanning word in ' $n$ ander referaat deur ' $n$ ekonoom behandel en dit is onnodig vir my om meer oor die saak te sê.

Geografie en sosiologie speel ook 'n belangrike rol in beplanning en die beplanner behoort heelwat van hierdie vakke te weet.

Al hierdie vakke d.w.s. aardrykskunde, ekonomie en sosiologie, dek 'n baie wye veld en dit is verkieslik om spesiale kursusse vir die beplanner in te stel. Persone wat hierdie vakke doseer het gewoonlik geen benul van beplanning nie en dit word aan die hand gedoen dat ' $n$ beplanningskursus vir hulle ingestel word. Die dosent in beplanning kan ook met voordeel die ander kursusse bywoon. Vir doeltreffende opleiding van beplanners moet die skakel tussen betrokke departemente versterk word.

Daar is ook etlike ander vakke soos fotointerpretasie, landskapbeplanning en ingenieurswese waarvan die beplanner sekere kennis moet hê. Beginsels, en nie detail nie, word benodig. Die beplanner wil nie ' $n$ pad- of spoorwegingenieur of 'n landskapargitek wees nie.

\section{Opsomming}

(a) Die tyd het aangebreek dat die teoretiese grondslag van beplanning verstewig word en die praktiese benadering beëindig word.

(b) Beplanning is nie net ontwerp nie. Sekere fasette van beplanning het geen ontwerp nodig nie.

(c) Die opleiding van beplanners behoort deur 'n onafhanklike departement of instituut waargeneem te word.

(d) Die opleiding van dosente is in die begin net so noodsaak- 
lik as die opleiding van studente.

(e) Die kernprogram moet baie sorgvuldig opgebou word, sodat gevorderde opleiding daarop kan uitbou.

(f) Navorsing moet gestimuleer word.

(g) Op die huidige tydstip is daar behoefte aan meer as een soort kursus bv. voorgraadse sowel as nagraadse opleiding van deskundiges in ander dissiplines.

Pretoria.

C. J. Viljoen. 